Supporting Information

\title{
Transition Metal Nitroprussides Examined for Water Harvesting and Sorption Cooling
}

Dushyant Barpaga ${ }^{1 \ddagger}$, Manish Shetty ${ }^{2 \ddagger}$, Jian Zheng ${ }^{2}$, Huamin Wang, ${ }^{1}$ B. Peter McGrail, ${ }^{1}$ Radha Kishan Motkuri ${ }^{1 *}$

${ }^{1}$ Energy and Environment Directorate, Pacific Northwest National Laboratory, Richland, WA 99352, USA.

${ }^{2}$ Physical and Computational Sciences Directorate, Pacific Northwest National Laboratory, Richland, WA 99352, USA.

These authors contributed equally to this work.

Corresponding Author:

*E-mail: Radhakishan.Motkuri@pnnl.gov 


\section{Table of Contents}

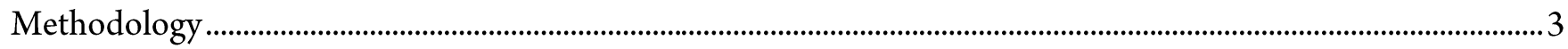

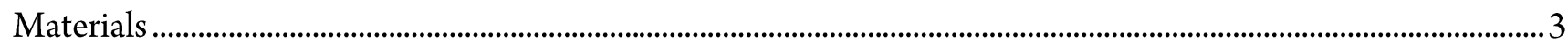

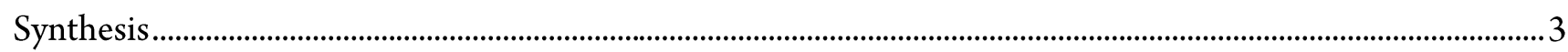

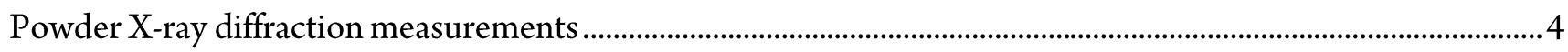

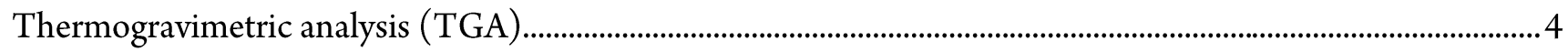

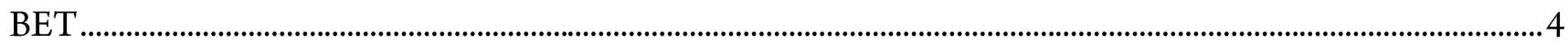

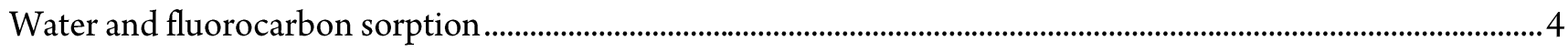

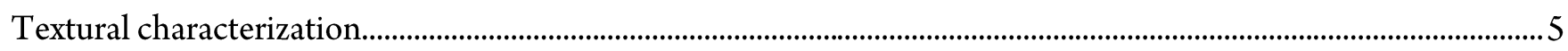

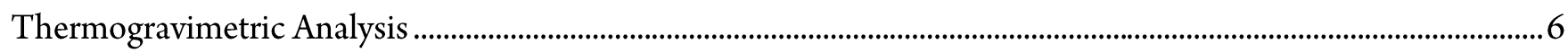

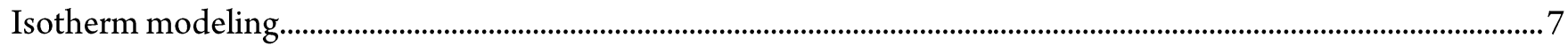

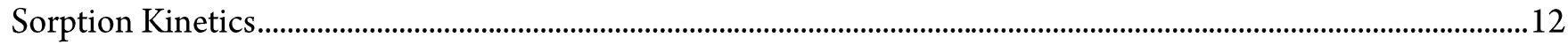

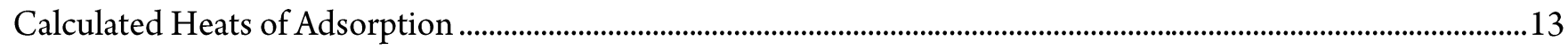

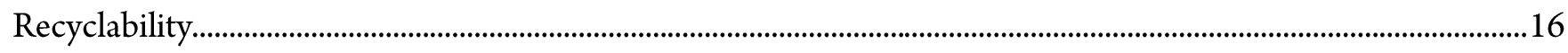

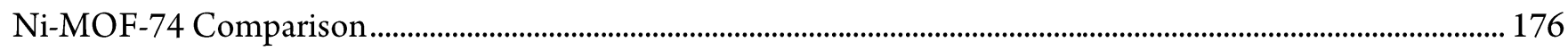




\section{Methodology}

\section{Materials}

Reagents and reagent-grade solvents were purchased from either Acros, Strem or Aldrich Chemical Company and used as received.

\section{Synthesis}

CoNP and NiNP are synthesized based on literature reports. ${ }^{1,2}$ For NiNP synthesis, approximately $100 \mathrm{~mL}$ of 0.05 M aqueous $\mathrm{Ni}(\mathrm{NO} 3)_{2} \cdot 6 \mathrm{H}_{2} \mathrm{O}(1.45 \mathrm{~g})$ solution was prepared. Additionally, approximately $100 \mathrm{~mL}$ of $0.05 \mathrm{M}$ aqueous $\mathrm{Na}_{2}\left(\mathrm{Fe}(\mathrm{CN})_{5} \mathrm{NO}\right) \cdot 2 \mathrm{H}_{2} \mathrm{O}(1.49)$ solution was also prepared. The sodium pentacyanonitrosylferrates solution was added dropwise to the metal salt solution while stirring. The combined solution was stirred at room temperature for 24 hours after which the precipitate was collected via centrifuge. The precipitate product was washed and centrifuged with deionized water $(3 \times 40 \mathrm{~mL})$, then methanol $(3 \times 40 \mathrm{~mL})$ every day for three days. After solvent exchange, the product was dried in a vacuum oven at $80^{\circ} \mathrm{C}$ overnight resulting in the synthesized NiNP material. Yield: $2.4 \mathrm{~g}$.

For CoNP synthesis, the same procedure was used as NiNP synthesis except $\mathrm{Co}\left(\mathrm{NO}_{3}\right)_{2} \cdot 6 \mathrm{H}_{2} \mathrm{O}(1.46 \mathrm{~g})$ metal salt was used instead of the nickel metal salt. Yield: $1.6 \mathrm{~g}$. 


\section{Powder X-ray diffraction measurements}

$\mathrm{XRD}$ was used to analyze the phase composition and structure of the samples. Experiments were performed with a Rigaku MiniFlex 600 X-ray diffractometer (XRD). The sample was placed in a powder sample holder under ambient conditions and a pattern was collected from the $2 \theta$ range of $1-60^{\circ}$. The step size was $2^{\circ} \min ^{-1}$.

\section{Thermogravimetric analysis (TGA)}

The thermogravimetric analysis (TGA) was performed using a thermoanalyzer SENSYS evo TG-DSC (SETARAM). $5 \mathrm{mg}$ of ample was placed in an alumina crucible $(100 \mu \mathrm{L})$ and the temperature was measured by using a thermocouple placed near the sample. Before heat, the sample was purged with pure $\mathrm{N}_{2}$ for $1 \mathrm{~h}$. Then the system was heated from room temperature to $150^{\circ} \mathrm{C}$ with a rate of $2^{\circ} \mathrm{C} /$ minute and help at $150^{\circ} \mathrm{C}$ for $10 \mathrm{~h}$.

\section{BET}

$\mathrm{N}_{2}$-physisorption information for pore volumes was obtained using a Micromeritics ASAP 2020 setup. A DFT method (using a carbon slit pore model with a N2DFT kernel) optimized for $\mathrm{N}_{2}$ on oxide surfaces, provided by the Micromeritics software suite, was applied to assess the micropore volume contributions. Single point adsorption close to $\mathrm{P} / \mathrm{P}_{0}=0.99$ was used to determine the total pore volume.

\section{Water and fluorocarbon sorption}

Both water and fluorocarbon R134a isotherms for the samples were collected gravimetrically using an Intelligent Gravimetric Analyzer (IGA) instrument. Prior to measuring the sorption studies, the sample was placed in a container of the IGA chamber and the weight of the sample was recorded before activation. The temperature of the furnace was increased up to $200^{\circ} \mathrm{C}$ under vacuum at a rate of $5^{\circ} \mathrm{C} / \mathrm{min}$ to remove the trapped solvent molecules. The sample was cooled to RT, its dry mass was set, and the experimental temperature $25^{\circ} \mathrm{C}$ was maintained by the IGA water bath. The static mode of the IGA was used to measure the sorption studies. The pressure points were set beforehand using the IGA software. The pressure was maintained at the set point by active computer control of the inlet/outlet valves throughout the duration of the experiment. Weight increases resulting from adsorption at each pressure step were plotted against the pressure. 


\section{Textural characterization}

Table S1: BET surface area, pore volume and pore size for Co and Ni nitroprussides.

\begin{tabular}{lll}
\hline & BET surface area $\left(\mathrm{m}^{2} \mathrm{~g}^{-1}\right)$ & Total pore volume $\left(\mathrm{cm}^{3} \mathrm{~g}^{-1}\right)$ \\
\hline Cobalt nitroprusside (CoNP) & 911 & 0.40 \\
Nickel nitroprusside (NiNP) & 976 & 0.62 \\
\hline
\end{tabular}


Thermogravimetric Analysis 


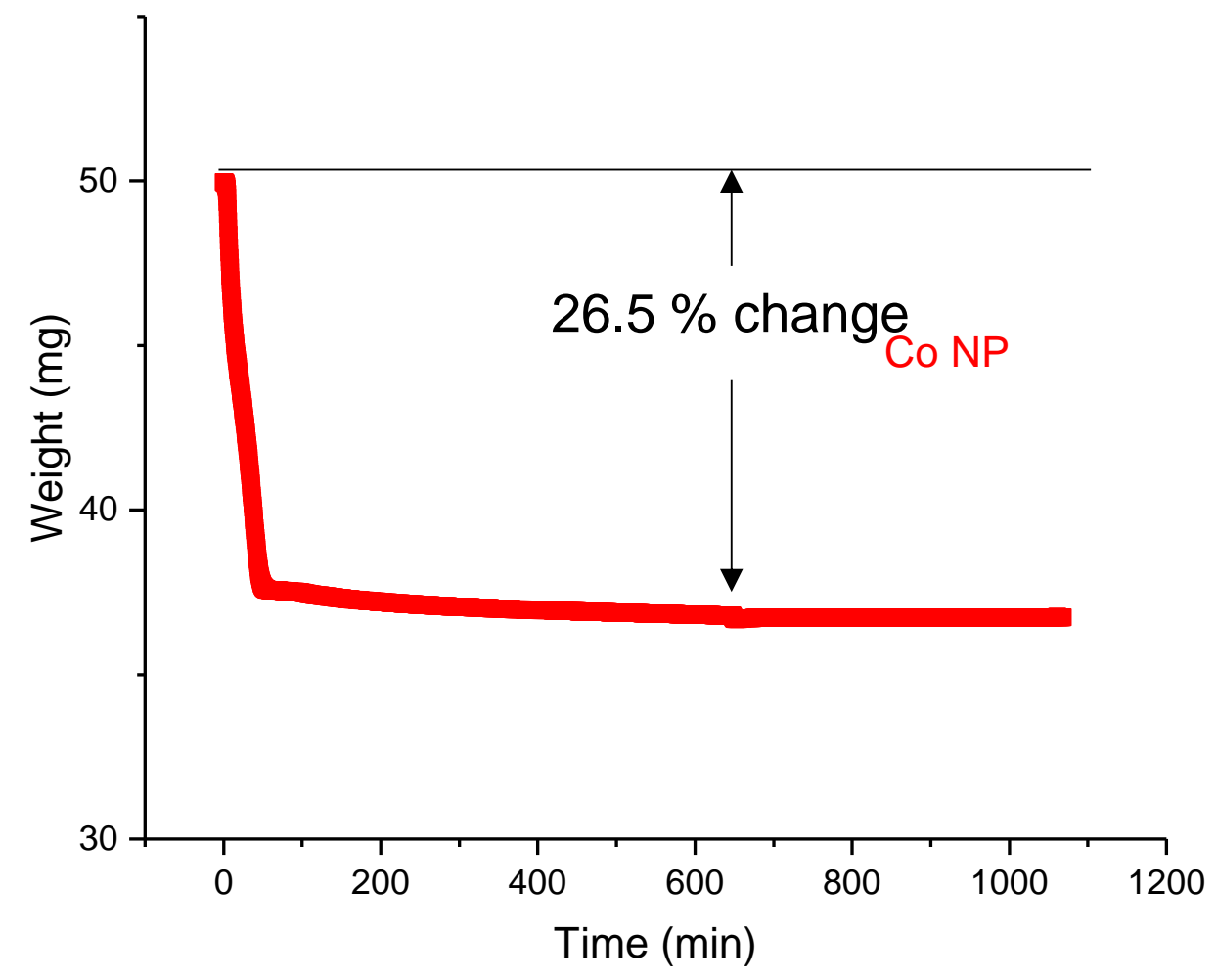

Figure S1: Thermogravimetric (TGA) analysis of Cobalt nitroprusside (CoNP).

\section{Isotherm modeling}

All adsorption isotherms for both water and fluorocarbon were fitted using the Multi temperature Toth model as described by Equations S1-S5. The experimental data collected at various temperatures for each sorbate-sorbent pair was regressed into the non-linear curve fitting model (via MATLAB) and the corresponding parameters characteristic of the Toth model were determined as shown in Table S2. 


$$
\begin{aligned}
& n=a \cdot P /\left(1+(b \cdot P)^{t}\right)^{1 / t} \\
& a=a_{0} \cdot \exp (E / T) \\
& b=b_{0} \cdot \exp (E / T) \\
& t=t_{0}+C / T \\
& H_{\text {ads }} \cong E \cdot R
\end{aligned}
$$

Equation S1-S5. Multi Temperature Toth adsorption model, where R is the ideal gas constant $(8.314 \mathrm{~J} / \mathrm{mol} \cdot \mathrm{K})$.

\begin{tabular}{|l|l|l|l|l|}
\hline$a_{0}\left(\mathrm{~mol}^{\prime} \mathrm{kg}^{-1} \cdot \mathrm{kPa}\right)$ & $\mathrm{E}(\mathrm{K})$ & $\mathbf{b}_{\mathrm{o}}\left(\mathrm{kPa}^{-1}\right)$ & $t_{\mathrm{o}}$ & $\mathrm{C}(\mathrm{K})$ \\
\hline
\end{tabular}

\begin{tabular}{|c|c|c|c|c|c|c|}
\hline \multirow{2}{*}{$\mathrm{H}_{2} \mathrm{O}$} & $\mathrm{CoNP}$ & $9.494 \times 10^{-5}$ & $4.601 \times 10^{3}$ & $2.715 \times 10^{-6}$ & $1.000 \times 10^{-2}$ & $1.220 \times 10^{2}$ \\
\cline { 2 - 6 } & $\mathrm{NiNP}$ & $8.154 \times 10^{-2}$ & $3.607 \times 10^{3}$ & $1.196 \times 10^{-3}$ & $1.000 \times 10^{-2}$ & $6.130 \times 10^{1}$ \\
\hline
\end{tabular}

\begin{tabular}{|c|c|c|c|c|c|c|}
\hline \multirow{2}{*}{$\mathrm{R} 134 \mathrm{a}$} & $\mathrm{CoNP}$ & $2.099 \times 10^{-4}$ & $3.509 \times 10^{3}$ & $4.827 \times 10^{-5}$ & $2.261 \times 10^{-1}$ & $1.970 \times 10^{1}$ \\
\cline { 2 - 6 } & $\mathrm{NiNP}$ & $1.000 \times 10^{-1}$ & $5.480 \times 10^{3}$ & $4.779 \times 10^{-3}$ & $9.037 \times 10^{-2}$ & $7.306 \times 10^{-13}$ \\
\hline
\end{tabular}

Table S2. Parameters characteristic of the multi temperature Toth adsorption model fitted for each sorbent-sorbate pair use to further extrapolate isotherms at any given temperature. 


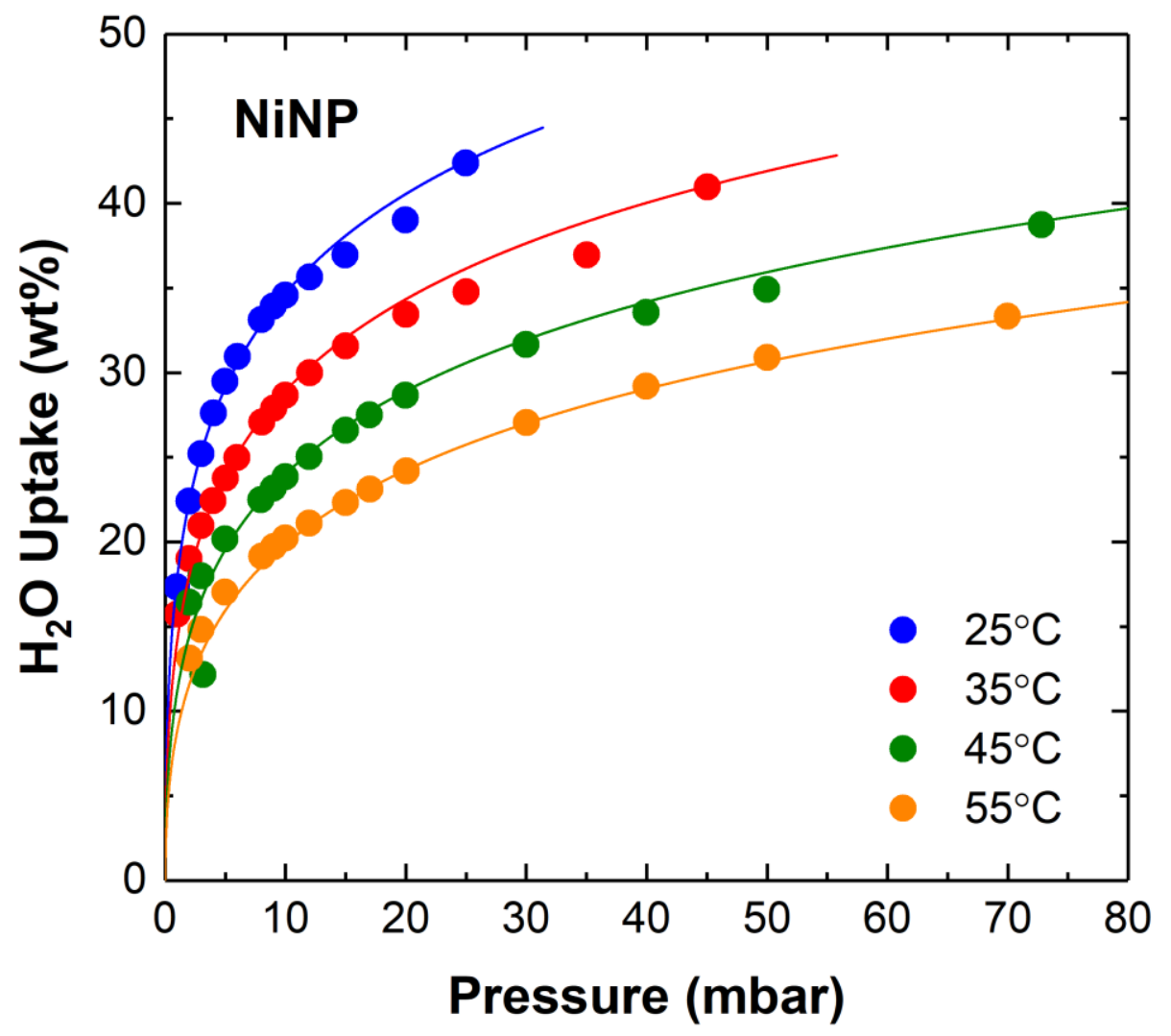

Figure S2: Water adsorption isotherms and corresponding fits for Ni nitroprusside, NiNP, at temperature range of $25-55^{\circ} \mathrm{C}$. 


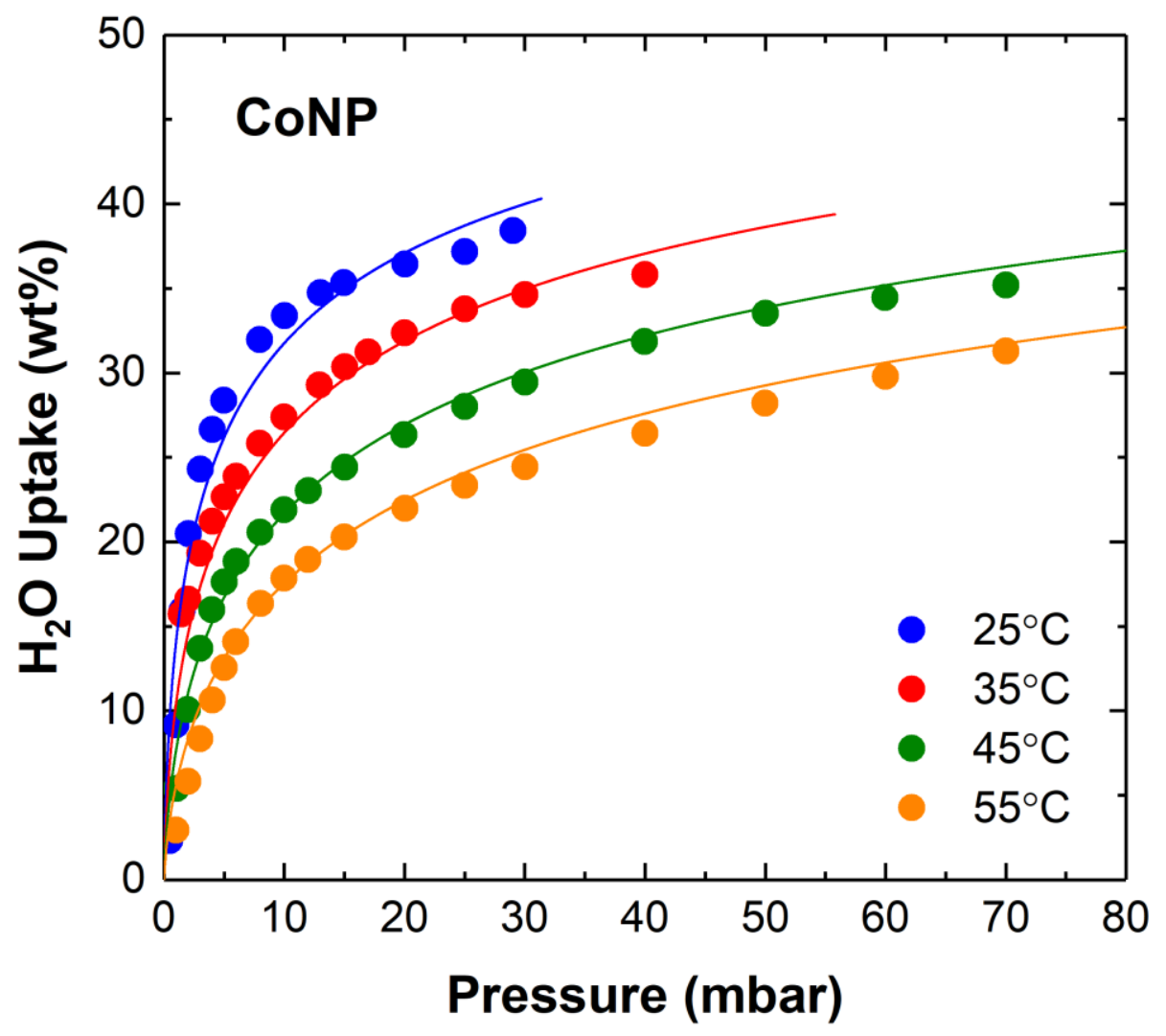

Figure S3: Water adsorption isotherms and corresponding fits for Co nitroprusside, CoNP, at temperature range of $25-55^{\circ} \mathrm{C}$. 


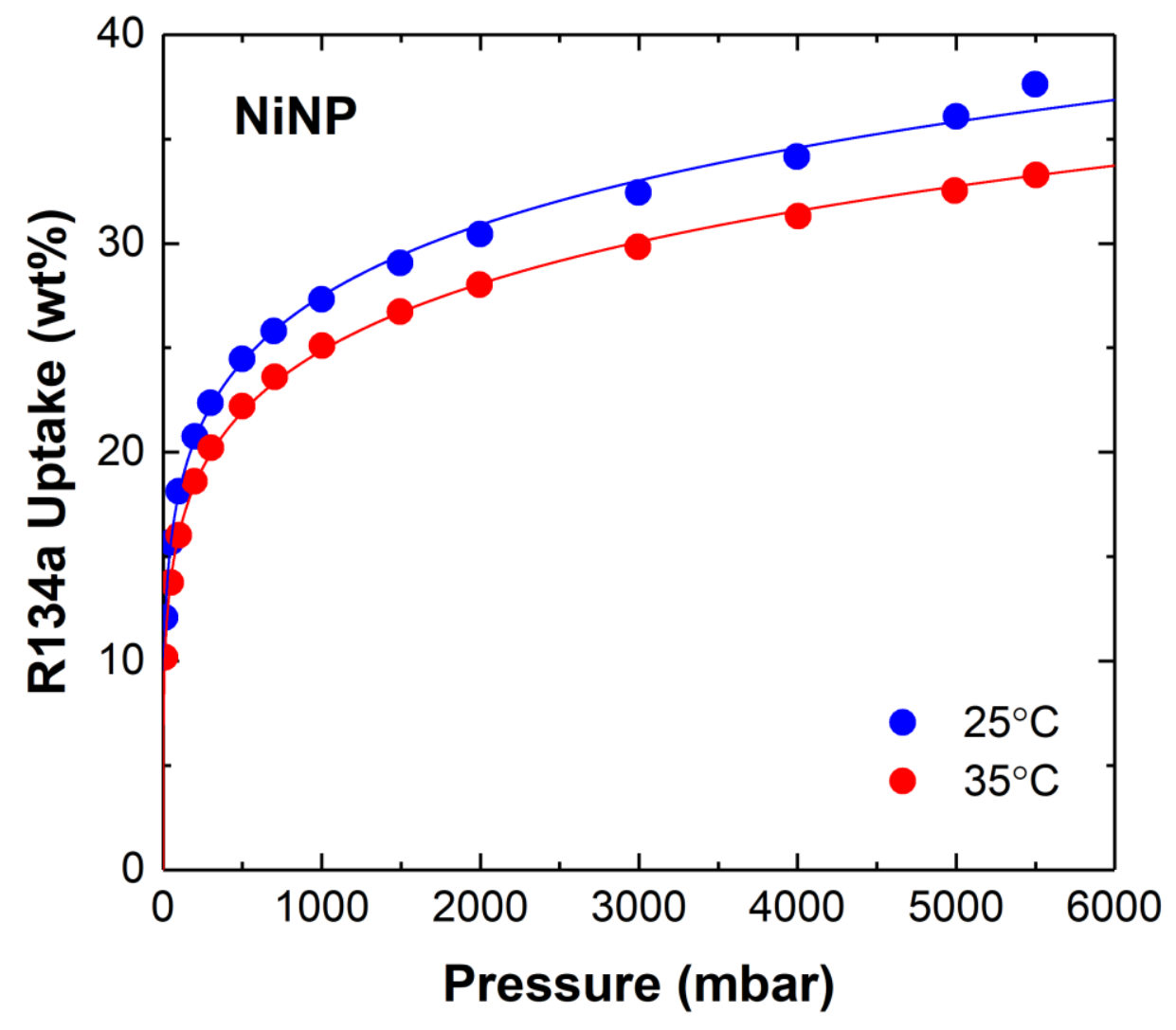

Figure S4: R134a adsorption isotherms and corresponding fits for Ni nitroprusside, NiNP, at temperature range of $25-35^{\circ} \mathrm{C}$. 


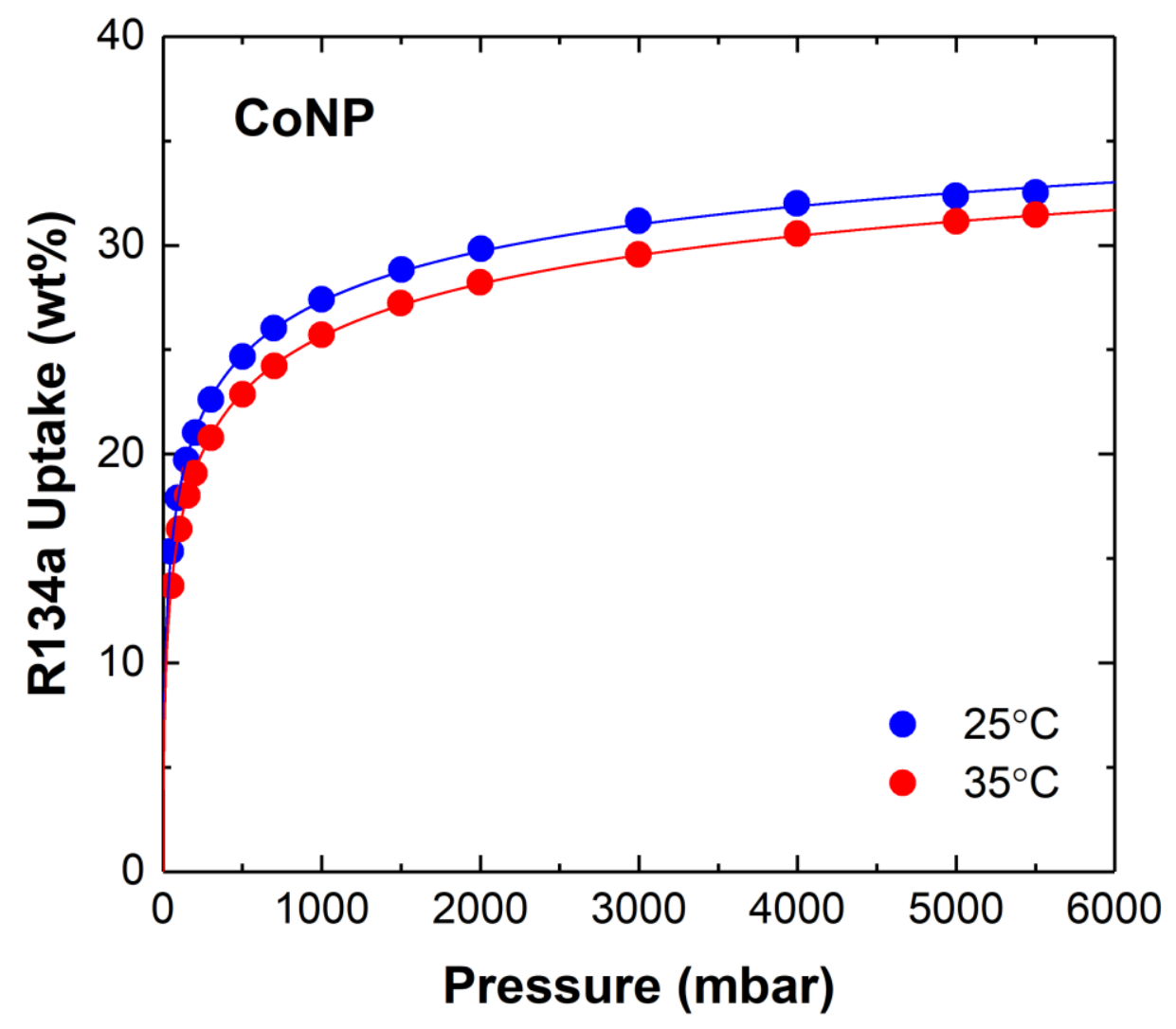

Figure S5: R134a adsorption isotherms and corresponding fits for Co nitroprusside, CoNP, at temperature range of $25-35^{\circ} \mathrm{C}$.

\section{Sorption Kinetics}



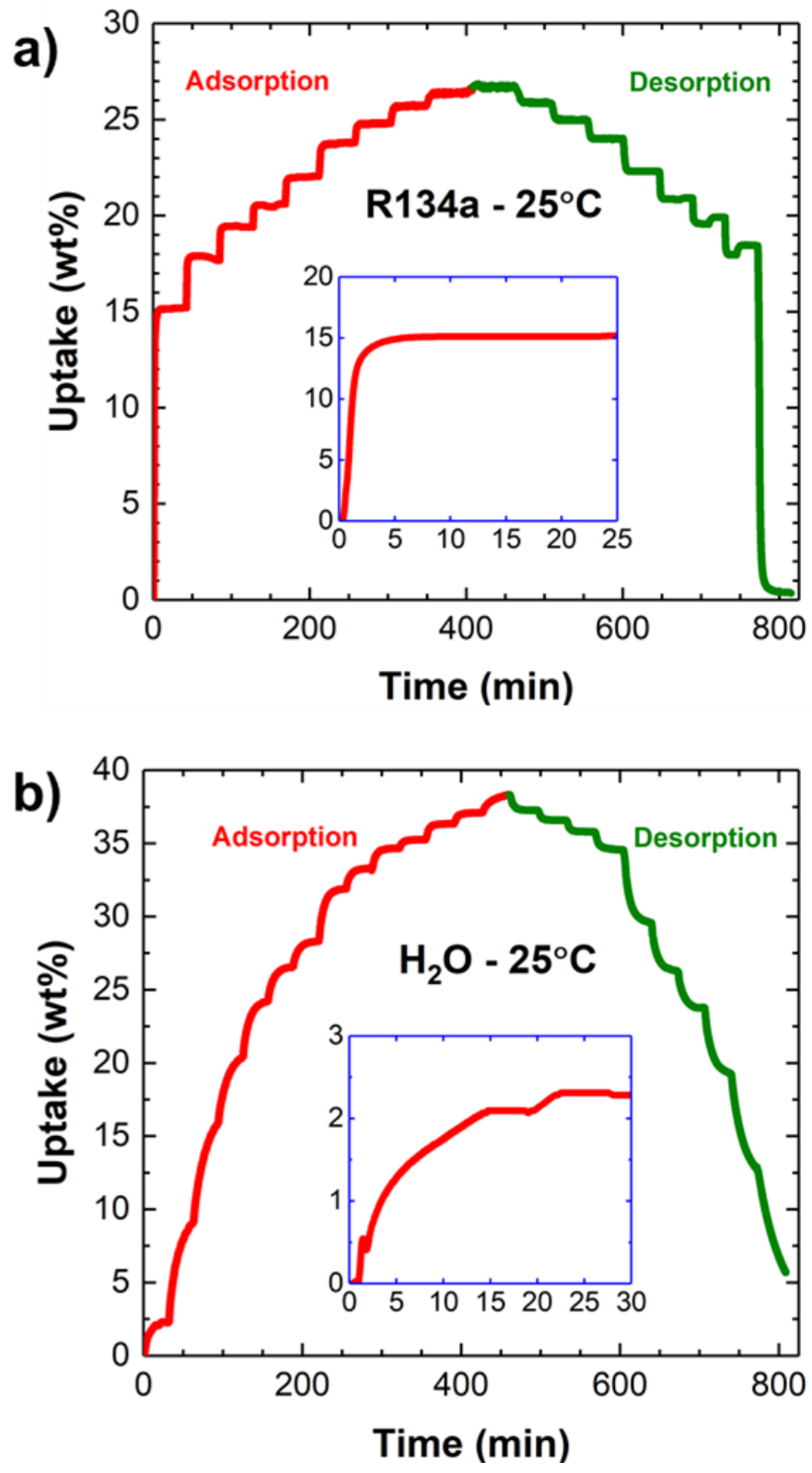

Figure S6. (a) Kinetics of R134a adsorption (red) and desorption (green) on CoNP at $25^{\circ} \mathrm{C}$. (b) Kinetics of $\mathrm{H} 2 \mathrm{O}$ adsorption (red) and desorption (green) on CoNP at $25^{\circ} \mathrm{C}$.

\section{Calculated Heats of Adsorption}




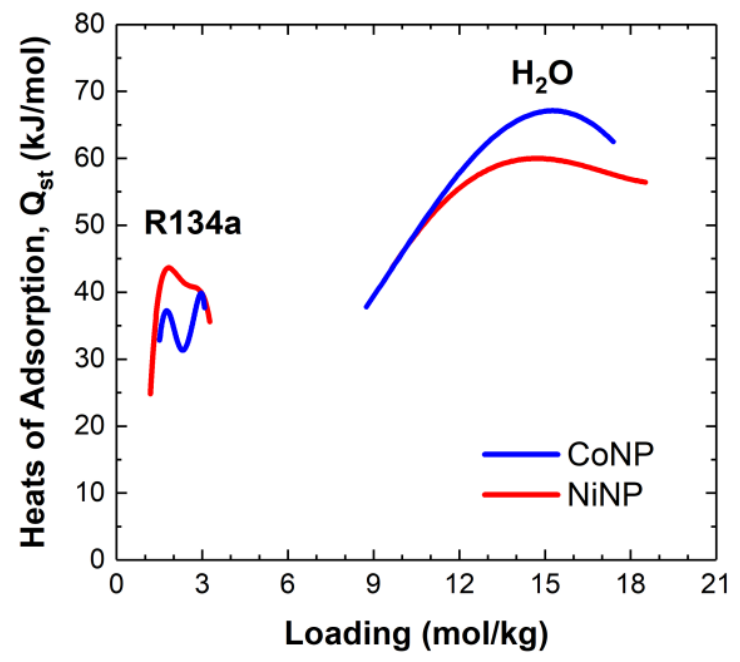

Figure S7: Heats of adsorption for both R134a and $\mathrm{H}_{2} \mathrm{O}$ on NPs as calculated using the Clausius-Clapeyron equation from experimentally collected multi-temperature isotherm data.

Table S3. Isosteric heats of adsorption comparison between nitroprussides and MOF materials. Note: For NPs, these approximated values are averages over the range of uptake measured as calculated based on experimental isotherm data collected at multiple temperatures in this work. 


\begin{tabular}{|c|c|c|}
\hline Sorbents & $\mathbf{H}_{2} \mathbf{O}(\mathbf{k J} / \mathbf{m o l})$ & $\mathbf{R 1 3 4 a}(\mathbf{k J} / \mathbf{m o l})$ \\
\hline NiNP & 53 & 35 \\
\hline CoNP & 58 & 36 \\
\hline Cu-BTC & $51^{3}$ & - \\
\hline ZIF-8 & $45^{4}$ & - \\
\hline Cr-MIL-101 & $45^{4}$ & $30^{5}$ \\
\hline Ni-MOF-74 & $63^{6,7}$ & $51^{6,7}$ \\
\hline Ni-TPM & $60^{6,7}$ & $44^{6,7}$ \\
\hline NU-1000 & $48^{5}$ & $30^{84}$ \\
\hline
\end{tabular}

S-15 


\section{Recyclability}

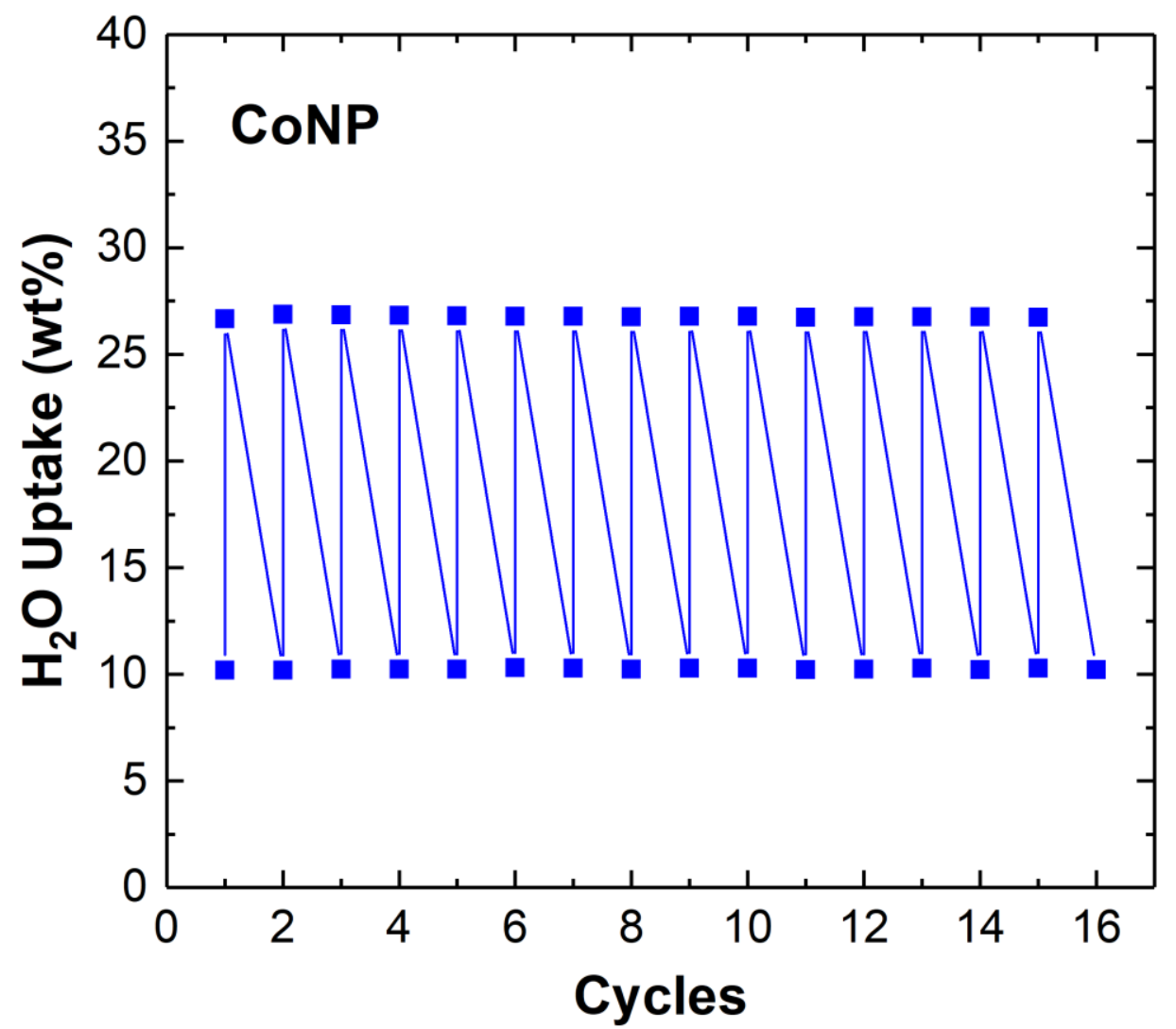

Figure S8: Cycling experiments with water sorption on CoNP showing consistent and reversible adsorption and desorption behavior. 


\section{Ni-MOF-74 Comparison}

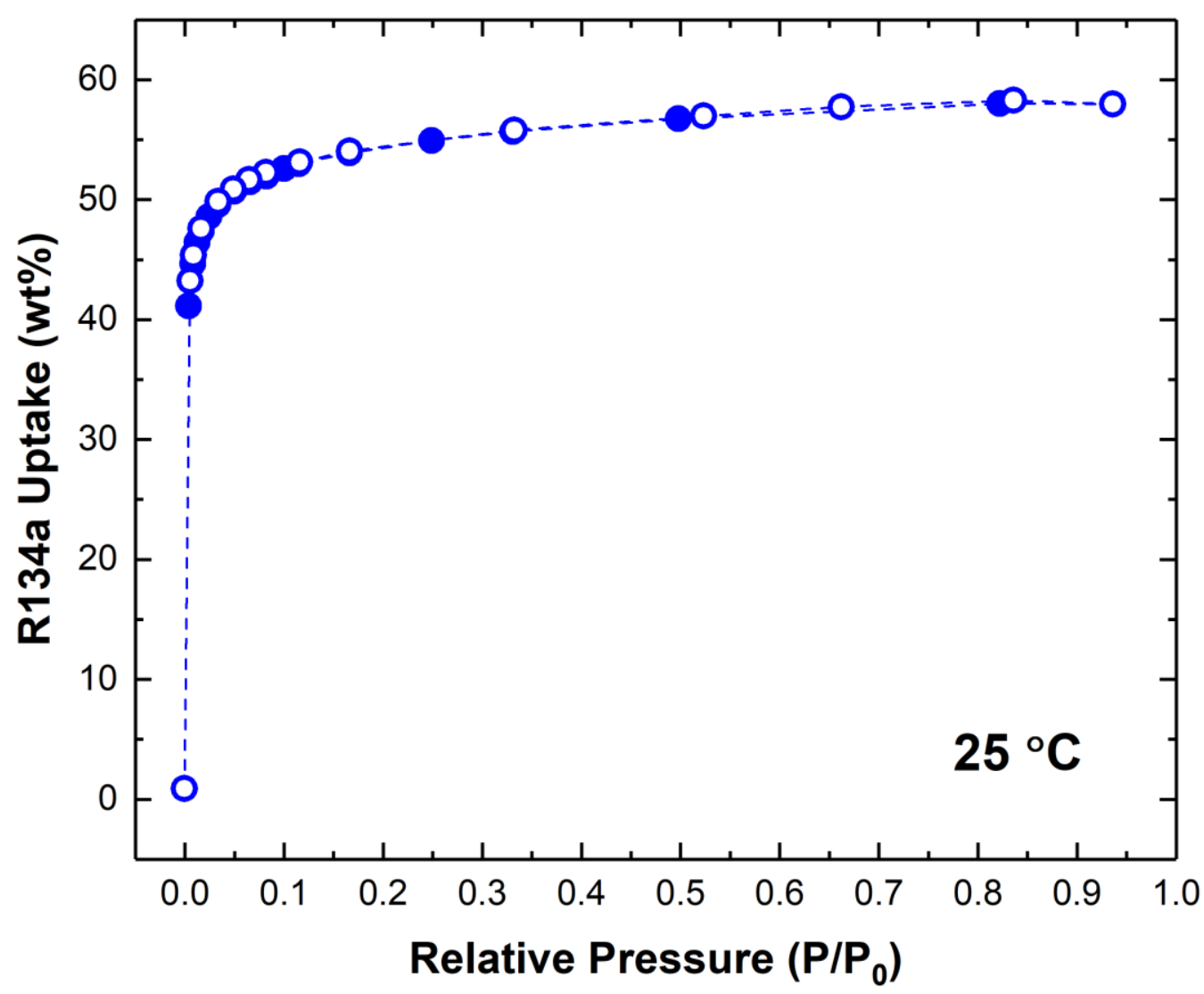

Figure S9: Fluorocarbon R134a sorption equilibrium isotherm on Ni-MOF-74 at $25^{\circ} \mathrm{C}$ for comparison with nitroprussides. Both adsorption points (filled circles) and desorption points (empty circles) are shown to emphasize lack of hysteresis. 


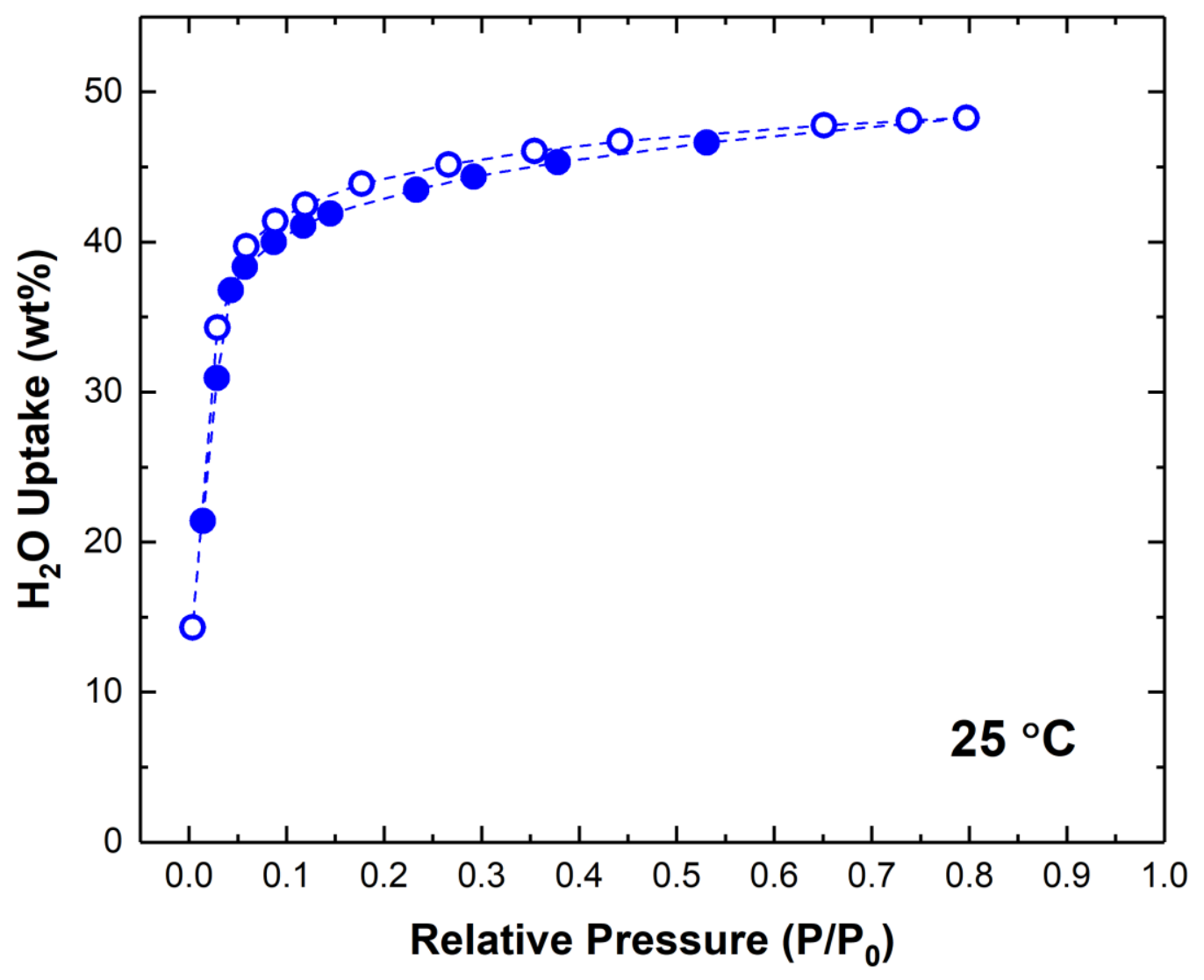

Figure S10: Water sorption equilibrium isotherm on Ni-MOF-74 at $25^{\circ} \mathrm{C}$ for comparison with nitroprussides. Both adsorption points (filled circles) and desorption points (empty circles) are shown to emphasize lack of hysteresis. 


\section{References:}

1. Devaramani, S.; Malingappa, P. Synthesis and Characterization of Cobalt Nitroprusside Nano Particles: Application to Sulfite Sensing in Food and Water Samples. Electrochim Acta 2012, 85, 579-587.

2. Devaramani, S.; Malleshappa, J.; Kempahanumakkagari, S.; Thippeswamy, R.; Mahalingappagari, P. Synthesis of Nickel Nitroprusside Coordination Nanoparticles by Simple Means: Its Characterization and Use as Electrochemical Sensor for Sulfide Estimation in Sewage and Water Samples. Int J Electrochem Sc 2014, 9, 46924708.

3. Henninger, S. K.; Jeremias, F.; Kummer, H.; Janiak, C. MOFs for Use in Adsorption Heat Pump Processes. Eur J Inorg Chem 2012, 2625-2634.

4. $\quad$ Kusgens, P.; Rose, M.; Senkovska, I.; Frode, H.; Henschel, A.; Siegle, S.; Kaskel, S. Characterization of metal-organic frameworks by water adsorption. Micropor Mesopor Mat 2009, 120, 325-330.

5. $\quad$ Motkuri, R. K.; Barpaga, D.; Zheng, J.; McGrail, B. P. Unpublished work.

6. Zheng, J.; Barpaga, D.; Trump, B. A.; Shetty, M.; Fan, Y.Z.; Bhattacharya, P.; Jenks, J.J.; Su, C. Y.; Brown, C. M.; Maurin, G.; McGrail, B. P.; Motkuri, R. K. Molecular Insight into Fluorocarbon Adsorption in Pore Expanded Metal-Organic Framework Analogs. J Am Chem Soc 2020, 142, 3002-3012.

7. Zheng, J.; Vemuri, R. S.; Estevez, L.; Koech, P. K.; Vargas, T.; Camaioni, D. M.; Blake, T. A.; McGrail, B. P.; Motkuri, R. K. Pore-Engineered Metal-Organic Frameworks with Excellent Adsorption of Water and Fluorocarbon Refrigerant for Cooling Applications. J Am Chem Soc 2017, 139, 10601-10604.

8. Zheng, J.; Barpaga, D.; Gutierrez, O. Y.; Browning, N. D.; Mehdi, B. L.; Farha, O. K.; Lercher, J. A.; McGrail, B. P.; Motkuri, R. K. Exceptional Fluorocarbon Uptake with Mesoporous Metal-Organic Frameworks for Adsorption-Based Cooling Systems. Acs Appl Energ Mater 2018, 1, 5853-5858. 